\title{
ASSOCIATION BETWEEN PARTICIPATION IN HIV/AIDS PEER GROUP, STIGMA, DISCRIMINATION, AND QUALITY LIFE OF PEOPLE LIVING WITH HIV/ AIDS
}

\author{
Mia Ashari Kurniasari1 ${ }^{1)}$, Bhisma Murti ${ }^{1}$, Argyo Demartoto²) \\ 1) Masters Program in Public Health, Sebelas Maret University, Surakarta \\ ${ }^{2)}$ Faculty of Social and Political Sciences, Sebelas Maret University, Surakarta
}

\begin{abstract}
Background: The quality of life of people living with HIV/ AIDS (PLH) is of public health concern and calls for attention. The quality of life of PLH may be affected by stigma and discrimination. Peer group of PLHs may have an important role in improving the quality of life of PLHs. This study aimed to investigate the association between participation in HIV/ AIDSpeer group, stigma, discrimination, and quality of life of PLHs.

Subjectsand Method: This was an analytic and observational study with cross sectional design. This study was conducted in Tulungagung, East Java, from November, 2016 to January, 2017. A total of 65 PLHs participating in HIV/ AIDS peer group and 35 PLHs not participating in HIV/ AIDS peer group were selected by fixed exposure sampling. The dependent variable was quality of life of PLHs. The independent variables were participation in HIV/ AIDS peer group, stigma, and discrimination. The data were collected by a set of questionnaire and analyzed using path analysis model.

Results: Participation in HIV/ AIDS peer group ( $b=0.27 ; \mathrm{p}<0.001)$, social support $(b=0.43 ; p<0.001)$, and family support $(b=0.18 ; p=0.021)$, had positive associations with a decrease in stigma and discrimination towards PLHs. Higher income $(b=0.33 ; p=0.026)$, higher education level $(b=0.21$; $\mathrm{p}<0.001)$, less stigma and discrimination $(\mathrm{b}=0.33$; $\mathrm{p}<0.001)$, had positive associations with quality of life of PLHs. Core self evalutionshowed positive association with quality of life of PLHs $(b=0.31 ; p<0.001)$.

Conclusion: Participation in HIV/ AIDS peer group, social support, and family support, are positively associated with a decrease in stigma and discrimination towards PLHs. Higher income, higher education, less stigma and discrimination, are positively associated with quality of life of PLHs. Core self evalutionis positively associated with quality of life of PLHs.
\end{abstract}

Keywords: HIV/ AIDS peer group, stigma, discrimination, social support, family support, quality of life

Correspondence: Mia Ashari Kurniasari. Masters Program in Public Health, Sebelas Maret University, Surakarta. Email: Deandagelis@gmail.com. Mobile: +62851216175293 . 